\title{
Open data in building resilience to recurrent natural hazards in remote mountainous communities of Nepal
}

\author{
Binod Prasad Parajuli¹, Puja Shakya ${ }^{1}$ Prakash Khadka², Wei \\ Liu $^{2}$, and Uttam Pudasaini ${ }^{3}$ \\ 1 Practical Action Consulting South Asia, 2 International Institute for Applied \\ Systems Analysis, 3 NAXA Private Limited
}

May 2020 


\section{Context}

- Nepal's mountainous parts are vulnerable to multiple hazards including landslides and floods (MoHA, 2013)

- Lack of geospatial data in better understanding the natural hazards and associated risks

- Most of the scientific data generated by scientists are not easily accessible by the users

- The risk related data generated by the researcher and scientist are too technical and is very difficult for target users to make sense for practical use (Ospina, 2018)

- Communities are mostly seen as a knowledge receiver, undermining the possibilities of co-creating the knowledge in a collaborative manners which creates a void between researcher and communities in capitalizing the opportunities of science in making societal benefits (Challies et al., 2016) 


\section{Research question}

- What is the potential of using technical knowledge of researchers and practical understanding of citizen scientists to co-produce a geospatial database in better understanding natural hazards using openly available platforms? 


\section{Objectives}

The main objective of this research is to pilot the collaborative approach of mapping resource, exposure and vulnerabilities to natural hazards by transferring the technical capacities to the citizen scientist.

Specific objectives;

- To train the citizen scientist selected from diverse background and age group on digital mapping technologies and instruments

- To leverage the technical expertise of researchers and practical understanding of citizen scientist to map the selected study sites

- To create a information repository in open platforms easily accessible by users and humanitarian actors in case of any future disasters 


\section{Methodology}

A. Study area

- Bajhang and Bajura districts of Sudurpaschim Province

$\checkmark$ Bajhang: Bitthadchir Rural Municipality

Total area: 86.68 sq. $\mathrm{km}$

$\checkmark$ Bajura: Municipality

Budhiganga

Total area: 59.52 sq. $\mathrm{km}$

- Elevation: 706 to 2747 m

- Climate zone: Tropical to Temperate

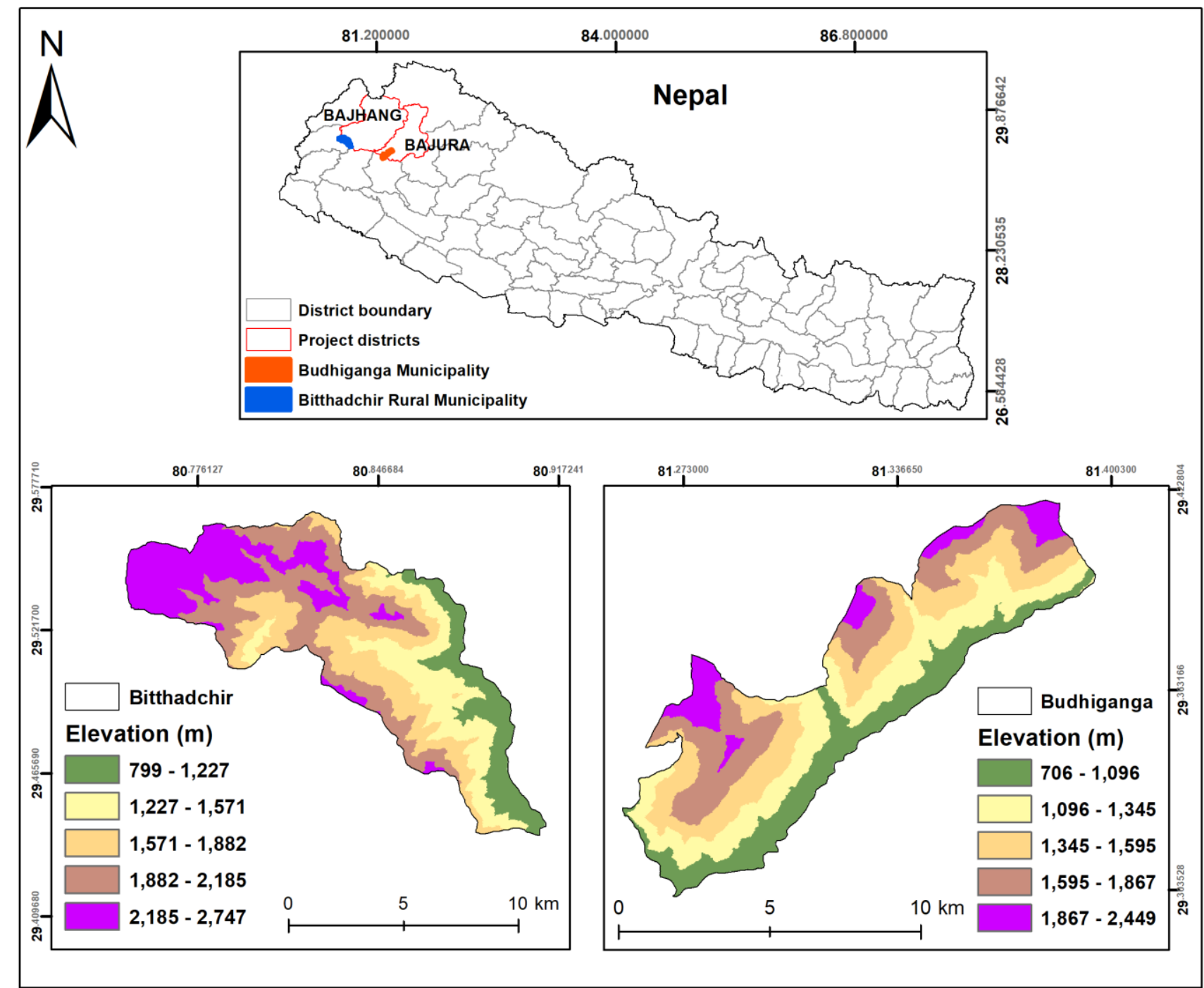

Figure 1: Study area map 


\section{Methodology}

B. Methods

Remote mapping using JOSM( Bing aerial imageries)

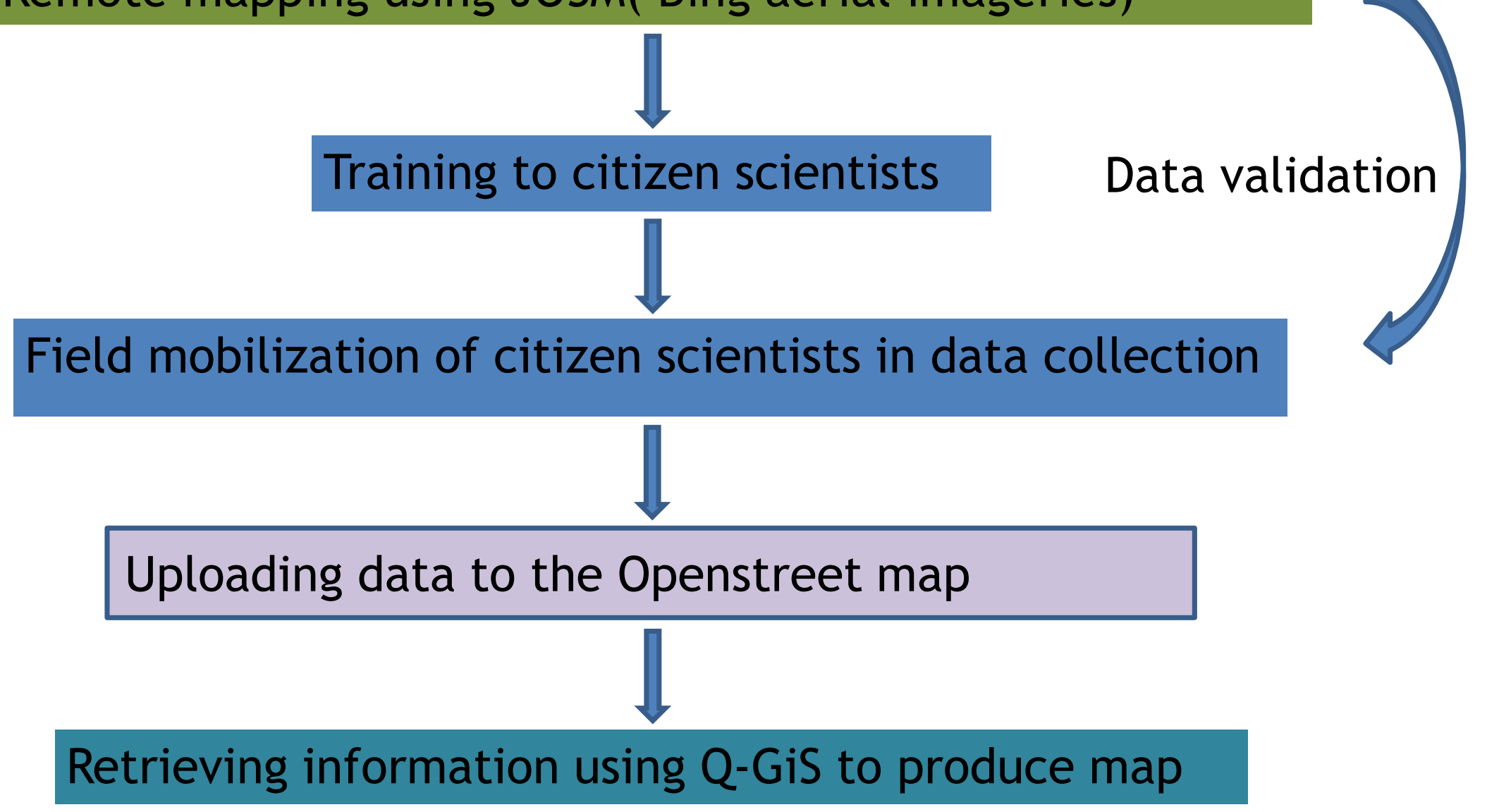




\section{Results}

1. More than 80 percent of the selected districts remotely mapped in the OpenStreet map using Bing aerial imageries and JOSM

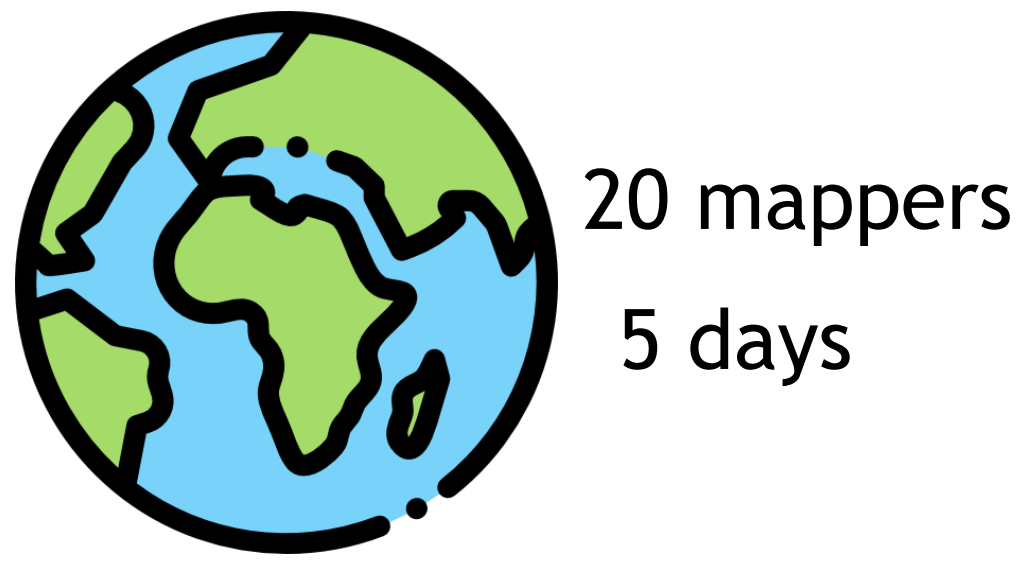

Attributes mapped

Roads, rivers, buildings, forest area , trails, open spaces and streams

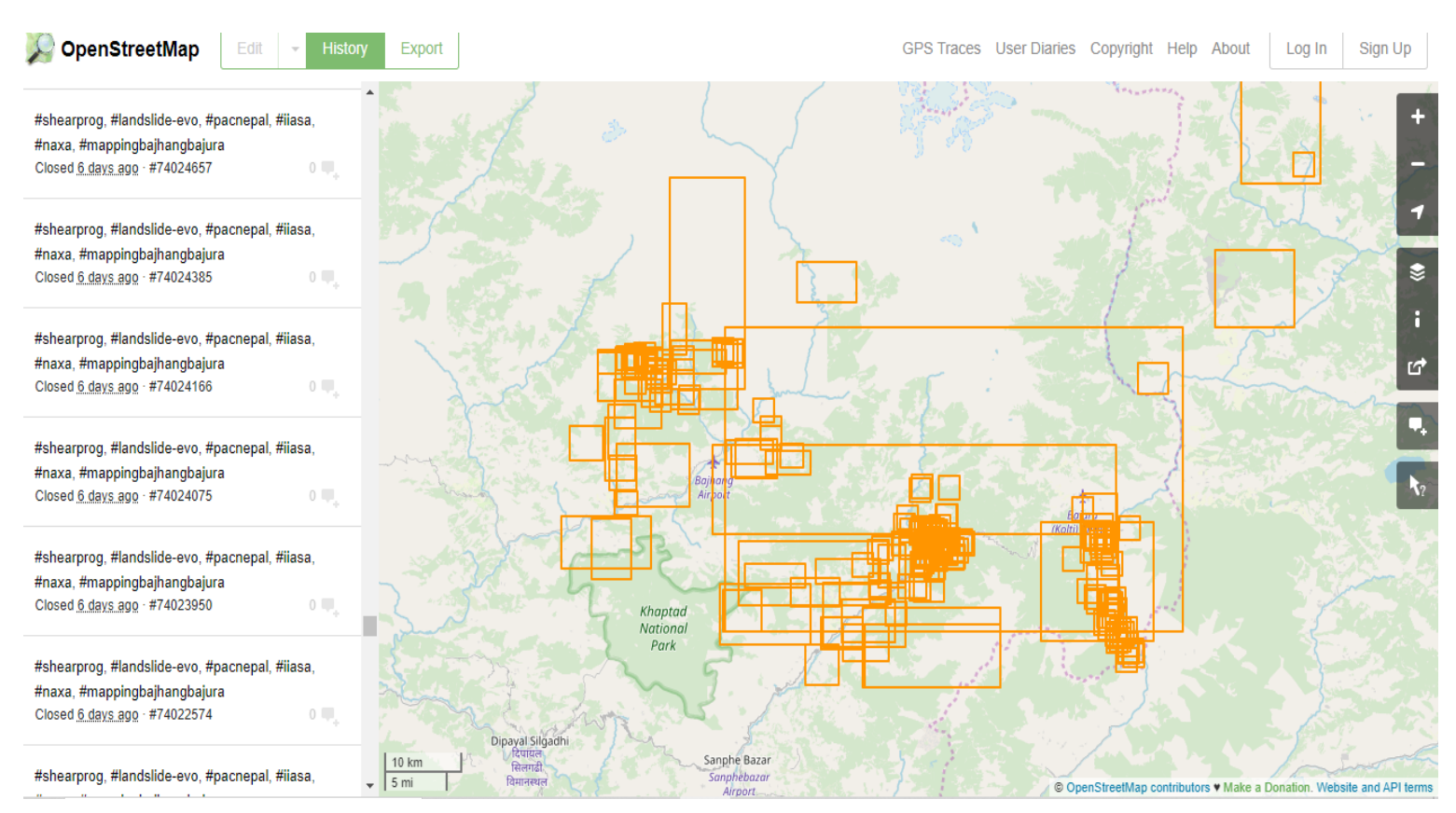

Figure 2: Snapshot of changes in OpenStreet map after remote mapping 


\section{Results}

\section{Training to citizen scientists}

\begin{tabular}{|l|l|l|l|}
$\begin{array}{l}\text { Number of } \\
\text { participants }\end{array}$ & $\begin{array}{l}\text { Number of } \\
\text { days }\end{array}$ & Area of capacity building & Instruments / software used \\
\hline 42 & 4 & $\begin{array}{l}\text { Map literacy and digital } \\
\text { mapping }\end{array}$ & $\begin{array}{l}\text { Garmin GPS, Smartphones with GPS } \\
\text { functionality, JOSM, OSM tracker and Q-GiS }\end{array}$ \\
\hline
\end{tabular}
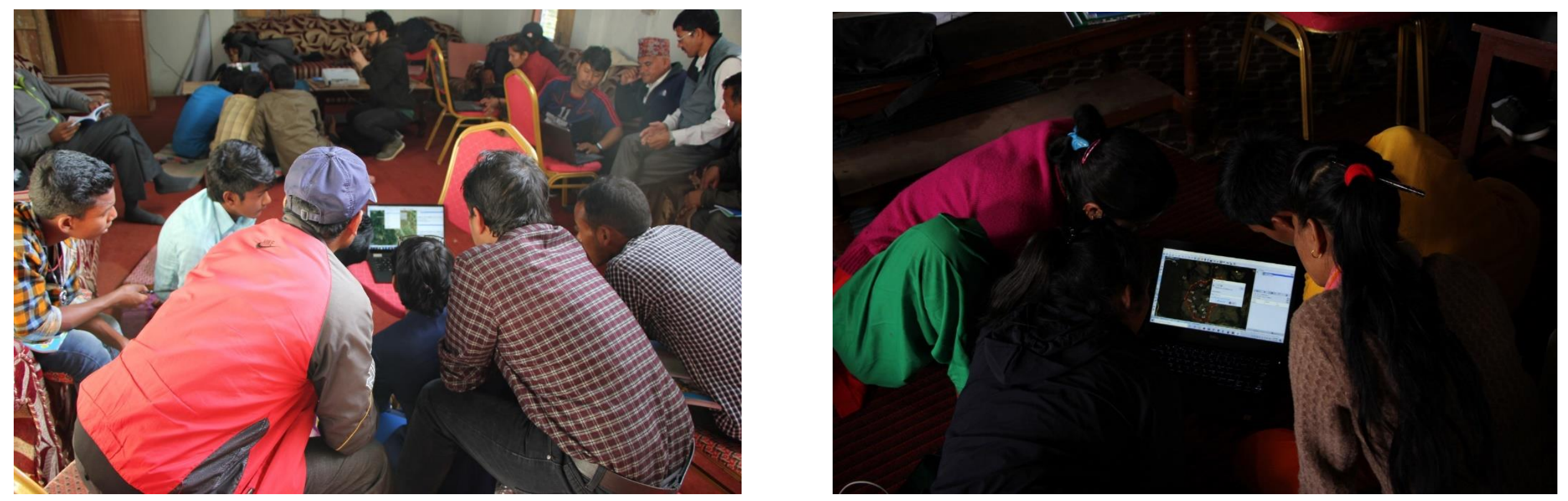

Figure 3: Participants learning digital mapping techniques 


\section{Results}

3. Ground based mapping of key landmarks and facilities of two local units and uploaded in the Openstreet map

Approximately $40 \mathrm{~km}$ of ground based mapping done

Data cleaning and uploaded to the OSM platform done by citizen scientists

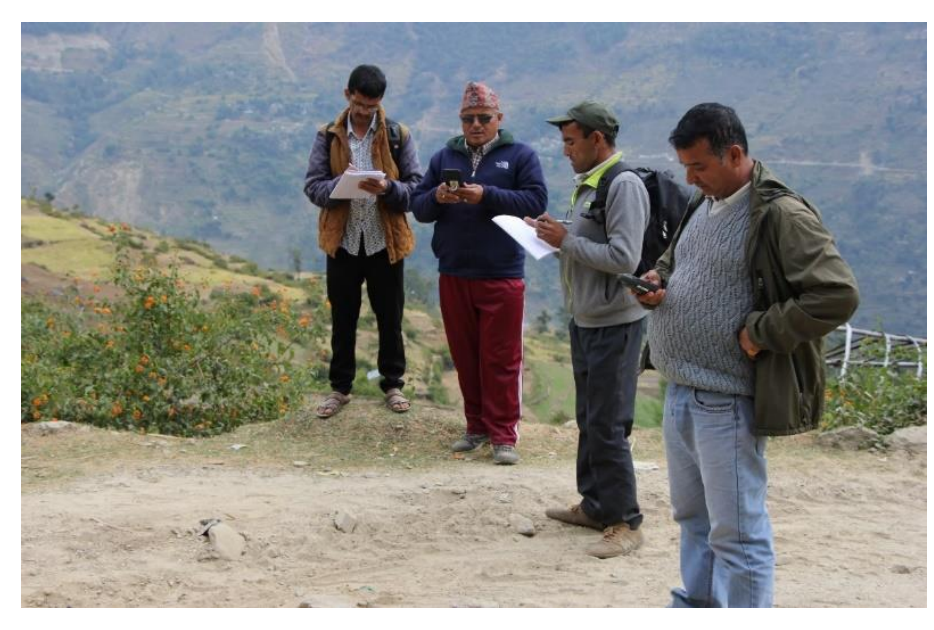

Figure 4: Participants collecting field data

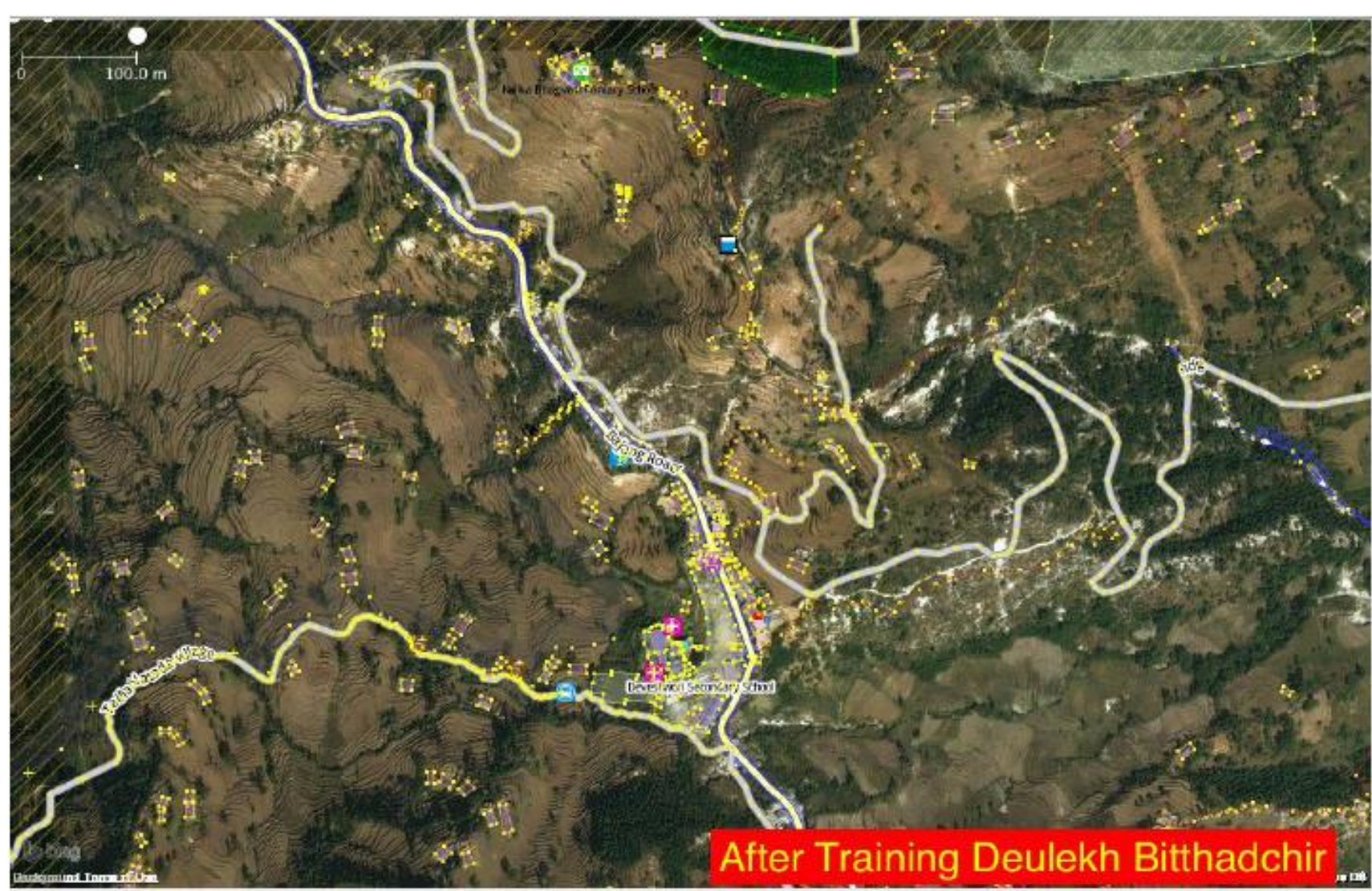

Figure 5: Study area after uploading the collected data and remote mapping in JOSM 


\section{Results}

4. Data Retrieval in Q-GIS and preparation of maps

- OSM map imported in the Q-GIS as a base map and key infrastructure and facilities visualized

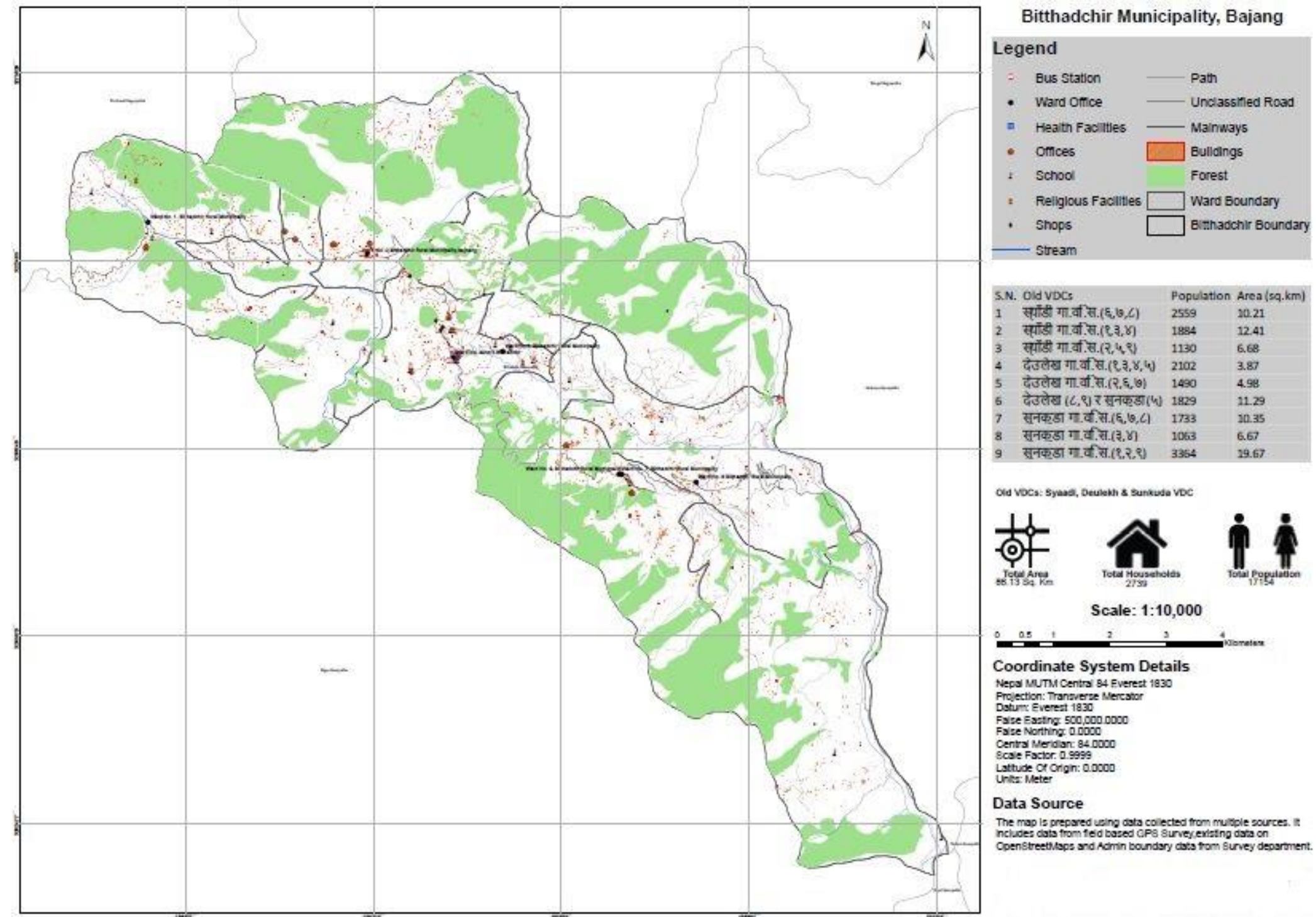

Figure 6: Map Produced in GIS after incorporating all the collected data 


\section{Conclusion}

This pilot study shows that there is a great potential of co- producing the risk knowledge by leveraging the technical knowledge of researchers and practical understanding of citizen scientists using openly available platforms. This knowledge could be crucial in better understanding natural hazards and strengthening resilience to disasters. 


\section{Way forward}

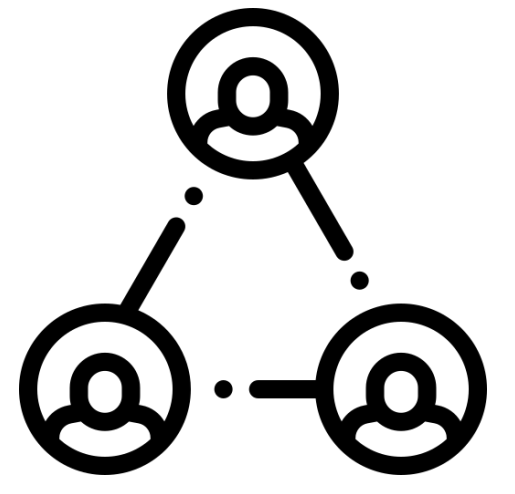

Mobilization

(More comprehensive data collection through citizen scientist)

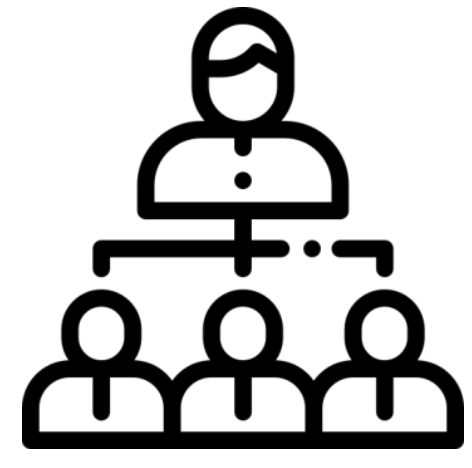

Consultation

(Workshop, planning meeting) (government, communities and media )

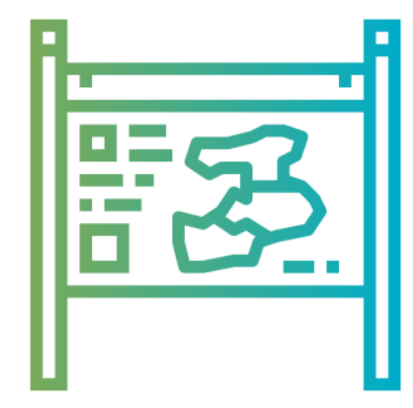

Dissemination

(Printing these collaboratively produced maps and installation as a hoarding board in public places) 


\section{Some Photographs}

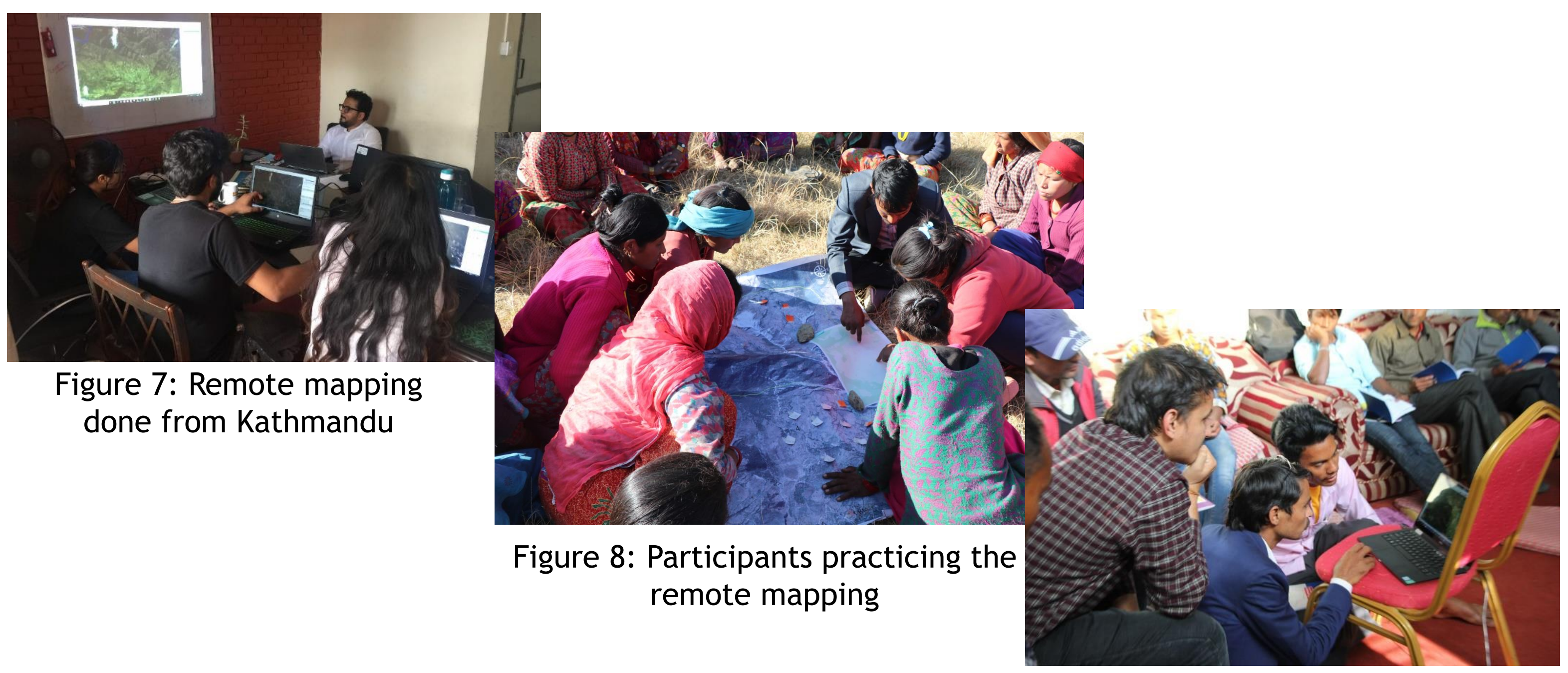

Figure 9: Community consolation and map literacy activities 


\section{References}

Challies, A. l., Newig, J., Thaler, T., Kochskämper, E., \& Keitel, M. L. (2016). Participatory and collaborative governance for sustainable flood risk management: An emerging research agenda. Environmental Science and Policy, 275-280.

MoHA. (2013). National Disaster Report . Kathmandu: Ministry of Home Affairs (MoHA), Government of Nepal; Disaster Preparedness Network Nepal (DPNet-Nepal).

Ospina, A. V. (2018). Big Data for resilience storybook: Experiences integrating Big Data into resilience programming. Winnipeg: International Institute for Sustainable Development. Retrieved from www.iisd.org 


\section{Acknowledgements}

We would like to express our gratitude to all the citizen scientist and landslide EVO project for this opportunity and collaboration. This study was conducted as a part of Landslide Environmental Virtual Observatory( LEVO) project on Citizen Science for Landslide Risk Reduction and Disaster Resilience building in Mountain Regions. This project is funded by NERC (Natural Environment Research Council) and DFID (Department for International Development) under the UK SHEAR (Science for Humanitarian Emergencies and Resilience) programme (grant number NE/P000452/1). 


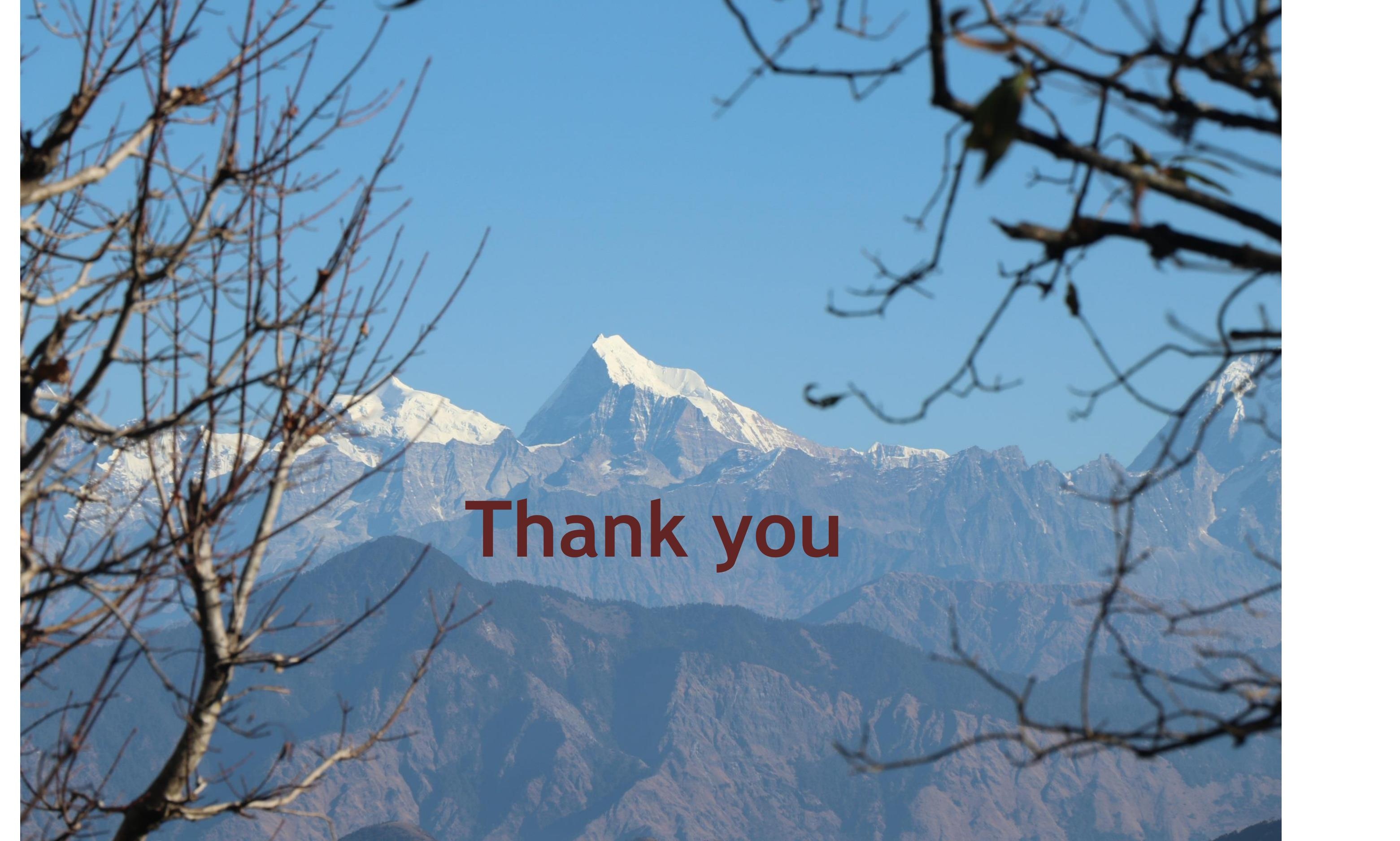

